BULLETIN Bulletin hispanique

HISPANIQUE Université Michel de Montaigne Bordeaux

118-1 | 2016

La Guerre Civile espagnole aujourd'hui (1936-2016)

\title{
Un enigma resuelto
}

Notas a los emblemas de la Expostulatio Spongiae

Julián González-Barrera

\section{(2) OpenEdition}

1 Journals

Edición electrónica

URL: http://journals.openedition.org/bulletinhispanique/4377

DOI: 10.4000/bulletinhispanique.4377

ISSN: 1775-3821

Editor

Presses universitaires de Bordeaux

Edición impresa

Fecha de publicación: 15 julio 2016

Paginación: 297-304

ISBN: 979-10-300-0058-0

ISSN: 0007-4640

Referencia electrónica

Julián González-Barrera, « Un enigma resuelto », Bulletin hispanique [En línea], 118-1 | 2016, Publicado

el 15 julio 2019, consultado el 07 septiembre 2019. URL : http://journals.openedition.org/

bulletinhispanique/4377 ; DOI : 10.4000/bulletinhispanique.4377 


\title{
Un enigma resuelto Notas a los emblemas de la Expostulatio Spongiae
}

\author{
Julián GonZÁLEZ-BARrerA \\ Universidad de Sevilla - España
}

Cet article essaie de découvrir la signification cachée des deux emblèmes qui illustrent l'Expostulatio Spongiae. Il s'agit d'une énigme parmi d'autres contenues dans ce livre fondamental qui permet de comprendre l'une des polémiques littéraires les plus importantes de l'Espagne du Siècle d'Or.

Mots-clés: Expostulatio Spongiae, emblèmes, Lope de Vega, Bible.

Este artículo trata de descubrir el significado oculto de los dos emblemas que ilustran la Expostulatio Spongiae. Un secreto de los muchos que encierra este libro fundamental para entender una de las polémicas literarias más importante de la España del Siglo de Oro.

Palabras claves: Expostulatio Spongiae, emblemática, Lope de Vega, Biblia.

This article tries to discover the hidden meaning of the two emblems illustrating the "Expostulatio Spongiae". One secret of many contained in this book, capital to understand one of the most important literary controversies of the Golden Age Spain.

Keywords: Expostulatio Spongiae, emblem studies, Lope de Vega, Bible.

T a Expostulatio Spongiae (1618), libro clave para entender las polémicas literarias del siglo XVII, presenta una serie de enigmas o interrogantes que hasta la traducción completa del texto parecían irresolubles ${ }^{1}$. Desde antiguo,

1. No sería hasta el año 2011 cuando saliera a la luz la primera traducción completa de la Expostulatio Spongiae, a cargo de Julián González-Barrera (Cf. Expostulatio Spongiae. Fuego cruzado en el nombre de Lope, Kassel, Reichenberger, «Estudios de literatura, 116», 2011). Para conocer en detalle la llamada guerra de la Spongia, acúdase al completo estudio que acompaña al texto traducido. 
una de las incógnitas que más interés ha suscitado entre la crítica es el significado oculto de los emblemas que ilustran sus páginas y que tienen en ambos casos a un escarabajo como protagonista. Ilustraciones que no responderían a un amplio propósito didáctico, como se presupone en esta clase de arte, sino a un objetivo más concreto y personal ${ }^{2}$, puesto que están dirigidas directamente a Pedro Torres Rámila, enemigo de Lope de Vega y autor de la Spongia, libelo incendiario al que la Expostulatio pretendía replicar.

Hasta la presente fecha, ningún estudioso del Siglo de Oro había conseguido dar una explicación más allá del significado literal o lógico de este conceptismo visual, tan del gusto barroco, por otra parte ${ }^{3}$.

\section{ODORE ENECAT SVO}

El emblema más llamativo de la Expostulatio se encuentra al final del Oneiropaegnion o Sueño jocoso (f. 81r). Se trata en apariencia de una composición original, pero con la particularidad de que Lope la volvería a utilizar catorce años más tarde para La Dorotea (1632), donde reaparece en los preliminares ${ }^{4}$. Presidido por el mote "ODORE ENECAT SVO» (Mata por su olor), se retrata a un gran escarabajo boca arriba, o sea muerto, junto a un rosal en flor. Abajo se lee el siguiente dístico: "Cuando el audaz escarabajo irrumpe en los jardines de Vega, / muere vencido por el fragante olor de la rosa» 5 .

Nada se sabe sobre el autor de este emblema, quizás fuera el propio Fénix, pero, como ya advirtiera V. Dixon ${ }^{6}$, puede ser que el dibujante se inspirara en uno de los Emblemas Morales de Sebastián de Covarrubias (1610). En este libro, bajo el mote "DISPAR EXITVS» (Distinto final), la Eucaristía aparece rodeada por una guirnalda de rosas que son libadas por unas abejas, mientras abajo en el suelo aparecen esparcidos varios escarabajos muertos ${ }^{7}$. El paralelismo es

2. Cf. Carlos Brito Díaz, "Odore enecat suo: Lope de Vega y los emblemas», en Literatura emblemática hispánica. Actas del I Simposio Internacional (La Coruña, 14-17 de Septiembre, 1994), ed. Sagrario López Poza, La Coruña, Universidad de La Coruña, 1996, p. 364.

3. Para una descripción iconográfica de estos emblemas, cfr. Javier Portús Pérez, Pintura y pensamiento en la España de Lope de Vega, Hondarribia, Nerea, 1999, p. 172.

4. Ni siquiera en la última edición crítica de La Dorotea, a cargo de Donald MacGrady (Real Academia Espańola-Galaxia Gutenberg, 2011), se reproduce este emblema, reservándole únicamente un brevísimo comentario en nota.

5. "Audax dum Vegae irrumpit Scarabeus in hortos / Fragantis periit victus odore rosae» (Julián González-Barrera, Expostulatio..., p. 302-303).

6. Cf. Victor Dixon, «Los Emblemas morales de Sebastián de Covarrubias y las comedias de Lope», en Estado actual de los estudios sobre el Siglo de Oro. Actas del II Congreso Internacional de Hispanistas del Siglo de Oro, coord. Manuel García Martín, Salamanca, Universidad de Salamanca, 2 vols., 1993, vol. I, p. 299.

7. En ningún caso se trata de una creación original de Covarrubias. Este emblema remite a la tradición medieval de los ejemplos y más concretamente al Libro de los gatos (s. XV), donde se puede leer la fábula [n ${ }^{\circ}$. 34] «Enxienplo de las abejas con los escaravatos», en el que las abejas son los Doctores y santos de la Iglesia y los escarabajos hombres malos y pecadores (Cf. Libro de los gatos, ed. Bernard Darbord, Paris, Séminaire d'Études Médiévales Hispaniques de l'Université 
meridiano, aunque con notables diferencias. Según el profesor Morby ${ }^{8}$, otro posible modelo sería uno de los emblemas contenidos en el Symbolorum et emblematum ex volatilibus et insectis desumtorum centuria tertia de Joachim Camerarius (1597). Similar al anterior, en este caso no hay símbolo eucarístico, solo el rosal y las abejas cercados de algunos escarabajos.

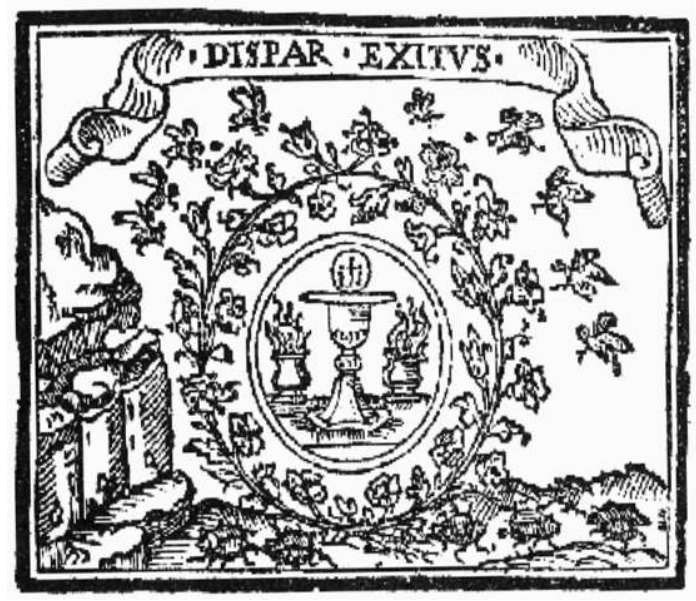

Fig. 1. - Emblemas Morales. Sebastián de Covarrubias (1610). Biblioteca Nacional, Madrid

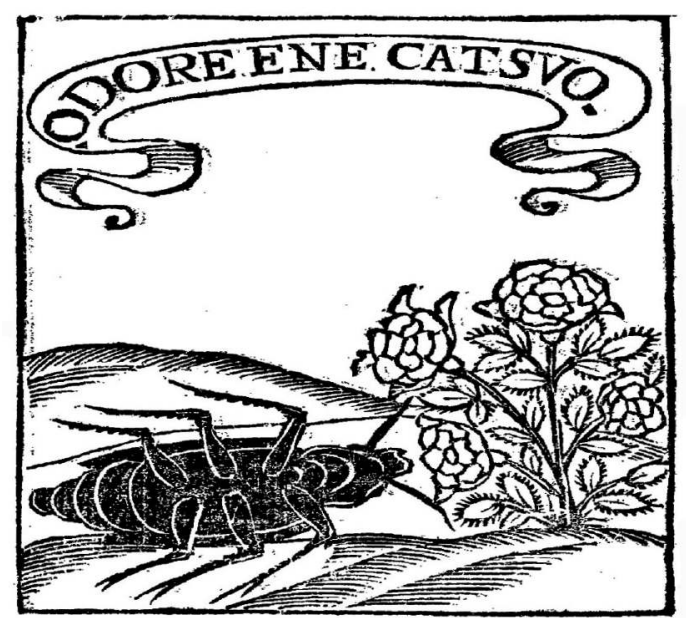

Fig. 2. - Expostulatio Spongiae (1618).

Biblioteca Nacional, Madrid

Paris XIII, 1984, p. 109-111).

8. Cf. Lope de Vega, La Dorotea, Edición, introducción y notas de Edwin S. Morby, Madrid, Castalia, 1987, nota p. 70 . 


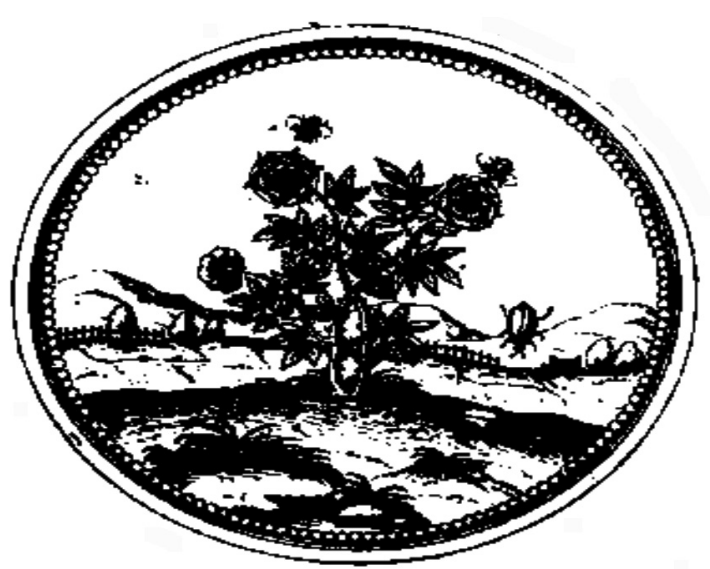

Fig. 3. - Symbolorum et emblematum. Joachim Camerarius (1597). Biblioteca Nacional, Madrid

Podría decirse que tanto la imagen del escarabajo como la del rosal no han dado muchos quebraderos de cabeza a la crítica. Parece evidente que la flor representaría a Lope y el insecto a Torres Rámila, aunque por motivos diferentes a los que comúnmente manejan los estudiosos. Porque no se trata de la excelsitud y la ignominia, respectivamente, como preconizara Brito Díaz 9 , sino de una potente alegoría religiosa compuesta para retratar moralmente al autor de la Spongia.

Para empezar, que los escarabajos mueran al oler las rosas es un lugar común desde la Antigüedad clásica. Probablemente basado en el principio de los contrarios, lo cierto es que Aristóteles (Mir. 845b), Plinio (NH. XI, 279) y Claudio Eliano (NA. VI, 46) ya lo señalan, entre otros. Desde tiempos inmemoriales los escarabajos han sido considerados como animales que traen mala suerte, por lo que no se les debe molestar, mucho menos hacerles daño. Una criatura hedionda que come, maneja y vive entre excrementos. En la tradición judeocristiana se les vincula con los hombres malvados, envidiosos y traicioneros, que prefieren vivir entre la inmundicia antes que seguir la ley de Dios (vid. n. 7). Al respecto, Covarrubias explica en su Tesoro de la lengua castellana: «Para decir que algún hombre o mujer es negro y de ruin talle, decimos que es un escarabajo» ${ }^{10}$.

Para el mundo pagano, el rosal fue imagen ancestral de la belleza, la juventud y el amor. Una metáfora manoseada hasta la náusea en la lírica. Sin olvidar que el hecho de que se dibuje sin abejas simplificaría aún más su interpretación. En las Sagradas Escrituras, en cambio, se lee en varias ocasiones como símbolo de la sabiduría (Ecl. 24, 18; 39, 17).

9. Cf. Carlos Brito Díaz, "Odore enecat suo...», p. 363.

10. Cf. Sebastián de Covarrubias, Tesoro de la lengua castellana, ed. Felipe C. R. Maldonado, Madrid, Castalia, 1995, p. 489. 
Para el cristianismo primitivo, la rosa, flor consagrada a Venus, se asoció pronto con la Virgen María, puesto que ella ya desde su nacimiento exhala el buen olor de Cristo, manifestándose así su virtud, pureza y futuro papel en la Encarnación. En la emblemática renacentista este motivo ya era conocido ${ }^{11}$. Una simbología cuya expresión paradigmática se halla en el Cántico espiritual de San Juan de la Cruz, cuando la rosa simboliza las bondades que anidan en el cristiano y el rosal por extensión las tres potencias del alma, que portan conceptos divinos, actos de amor y virtudes ${ }^{12}$. Una imaginería sagrada que nos arrimaría un poco más al mensaje oculto en el emblema, pero que aún resultaría insuficiente para explicar el verdadero papel del rosal [Lope] en la muerte del escarabajo [Torres Rámila].

La clave para descifrar el emblema se encuentra en una de las comedias del Fénix, concretamente en El maestro de danzar (1594). En un momento determinado, uno de los personajes enumera la influencia de los cinco sentidos como mediadores en el enamoramiento: en primer lugar, el amor entra por la vista; después, por el oído; y más adelante, por el olfato. Sobre este último dice:

\author{
Y pues llaman buen olor \\ a la opinión, nombre y fama, \\ ese sentido se llama \\ la tercera del amor ${ }^{13}$.
}

Lope no se inventa nada. La fama o buena reputación posee una trascendencia bíblica asociada a los cinco sentidos, más concretamente con el olfato. En el Cantar de los Cantares se proclama: «Es tu nombre ungüento derramado» $(1,2)^{14}$. Bien conocido es el pasaje del Evangelio de San Juan donde la hermana de Lázaro lava los pies a Jesucristo, llenando la casa de perfume: «María, tomando una libra de ungüento de nardo legítimo, de gran valor, ungió los pies de Jesús y los enjugó con sus cabellos, y la casa se llenó del olor del ungüento» (Jn 12, 3). Así, en la segunda Epístola a los Corintios, San Pablo interpretó este episodio de manera alegórica, arrogándose la misión divina de evangelizar, es decir, esparcir la fragancia de Cristo por toda la Tierra:

Con todo, doy gracias a Dios, que nos hace triunfar en Cristo, y por nosotros manifiesta en todo lugar el aroma de su conocimiento: porque somos para Dios penetrante olor de Cristo en los que se salvan y en los que se pierden; en éstos, olor de muerte para muerte; en aquéllos, olor de vida para vida (2Cor 2, 14-16).

11. «... dans la droite ligne de Piero Valeriano pour qui la mort du scarabée représentait l'affaiblissement spirituel causé par la frivolité et pour qui la rose était avant toute chose le signe de la grâce» (Christian Bouzy, «Dites-le avec des emblèmes: mythes, symboles et botanique dans les Lettres espagnoles au Siècle d'Or» en Flore au Paradis. Emblématique et vie religieuse aux $X V I^{e}$ et XVII siècles, Présentation de Paulette Choné et Bénédicte Gaulard, Glasgow, Glasgow Emblem Studies, 2004, p. 84).

12. Cf. San Juan de la Cruz, Cántico espiritual y poesía completa, eds. Paola Elía y María Jesús Mancho, Barcelona, Crítica, 2002, p. 171.

13. Cf. Lope de Vega, El maestro de danzar, en Obras completas. Comedias, I, eds. Jesús Gómez y Paloma Cuenca, Madrid, Turner-Biblioteca Castro, 1993, p. 587.

14. ungüento: perfume, en su sentido bíblico. 
No obstante, fue la oratoria sagrada, omnipresente en el período barroco, la que se encargó de propagarlo, recurriendo a la auctoritas de la Patrística y sobre todo gracias a la célebre homilía de San Agustín acerca de este pasaje de los Evangelios, donde se va a identificar el perfume de Cristo con el conocimiento de la fama divina, es decir, con la Verdad detrás de la palabra del Hijo de Dios: vida, fe, justicia, perdón, etc ${ }^{15}$. Fama, empero, que no está libre de los ataques de los envidiosos:

Pues bien, la casa se llenó del olor, el mundo se ha llenado de la buena fama, porque olor bueno es la buena fama. [...] Escucha al Apóstol: Somos en todo lugar, afirma, olor bueno del Mesías. [...] Felices quienes viven gracias al olor bueno; en cambio, ¿qué más infeliz que los que mueren por el olor bueno? ¿Y, pregunta alguno, a quién mata el olor bueno? [...] no debe denegarse a vosotros cómo es, cómo de modos admirables hace Dios esto: que con el olor bueno vivan los buenos y mueran los malos. La fama diseminaba en todas partes que el apóstol Pablo obraba bien, vivía bien, de palabra predicaba la justicia, la demostraba con los hechos, doctor admirable y dispensador fiel; unos le querían, otros le envidiaban. [...] Si has amado a quien obra bien, estás vivo por el olor bueno; si has envidiado a quien obra bien, estás muerto por el olor bueno. [...] No envidies y no te matará el olor bueno. (Aug., IJE 50, 7-8).

El sermón del obispo de Hipona no deja lugar a la duda. Aquellos que viven y obran bien [San Pablo - Lope] exhalan el fragante olor de Cristo. Un perfume de vida para el bueno y de muerte para el malo. Si envidias a quien obra bien estás condenado a morir por el aroma de su buena fama. Por consiguiente, el emblema avisa a Torres Rámila [el escarabajo] que envidiando la vida y obra de Lope [los jardines de Vega] acabará muriendo ante la fragancia de sus rosas [la virtuosa fama del poeta]. Una muerte espiritual, se entiende, que le condenará a la infelicidad, primero, y a la perdición y el infierno después, como avisa la doctrina cristiana.

\section{SVO SE LUMINE PRODIT}

En realidad, el segundo emblema que trataremos de descifrar es el primero que ilustra la Expostulatio Spongiae. Concretamente, se puede leer como antesala a la parte central o doctrinal, que le da título a la obra. Gobernado por el mote exterior «SVO SE LUMINE PRODIT» (Se delata por su luz), se perfila un solitario escarabajo con una velita encendida en la espalda. Abajo leemos el siguiente dístico: «¿Por qué los niños clavan velitas en la espalda del escarabajo?, / ¿acaso no se delata bastante por su olor?» ${ }^{16}$.

15. El obispo de Hipona no es el único que se ocupó de este asunto. Asimismo, San Gregorio de Nisa (Padre de la Iglesia griega) en su Comentario al Cantar de los Cantares o San Gregorio Magno (Padre de la Iglesia latina) en el Expositio in Canticum canticorum le dedicaron una exégesis detenida al perfume de Cristo.

16. "Cur pueri dorso scarabei lumina figunt, / nonne satis sese prodit odore suo» (Cf. Julián González-Barrera, Expostulatio..., p. 164-165). 


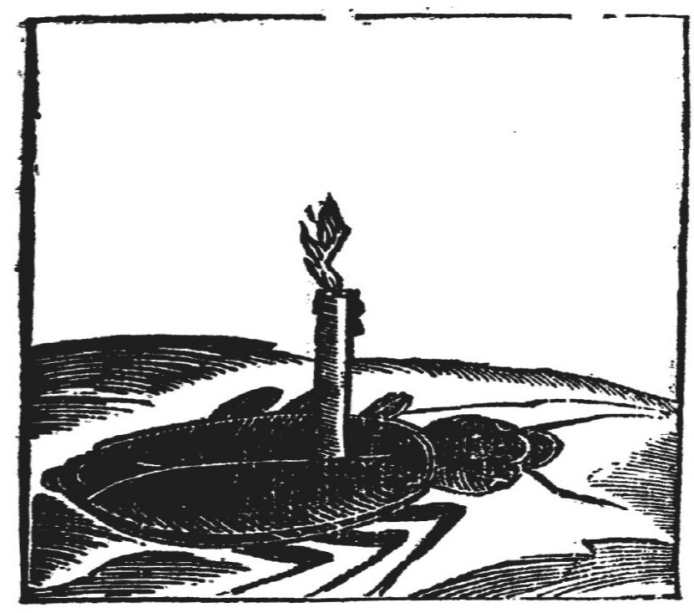

Fig. 4. - Expostulatio Spongiae (1618).

Biblioteca Nacional, Madrid

En este caso se trata de una composición ad hoc, escrita por y para la guerra literaria de la Spongia, y que no nos consta que se volviera a reproducir en ningún otro sitio. Además, es posible que estemos ante una creación original, pues no encontramos nada parecido en las colecciones de emblemas más conocidas de los siglos XVI y XVII ${ }^{17}$.

En un plano general, el significado oculto de esta pieza no se aparta demasiado de la anterior. Como cabría pensar, el escarabajo representa a Torres Rámila, objetivo de las críticas en la Expostulatio. De nuevo, el motivo bíblico del olor de muerte que desprenden los hombres malvados, envidiosos y maledicentes, que no aceptan o desconocen las virtudes del buen cristiano. El sentido religioso se extiende a la vela encendida, símbolo de la luz de los maléficos que está condenada a extinguirse cuando le alcance la justicia divina. Así, en el libro de Job descubrimos los castigos que esperan al que se aparta de Dios:

¿Cuándo pondrás fin a los vanos discursos? Reflexiona primero y luego hablaremos. ¿Por qué nos tomas como bestias y pasamos a tus ojos por estúpidos? Tú, que en tu furor te desgarras a ti mismo, ¿crees acaso que sin ti quedará despoblada la tierra, y lanzarás de su lugar las rocas? Sí, se apagará la luz de los perversos, no brillará la llama de su hogar. Apagarase la luz en su tienda y se extinguirá la vela sobre él [...] Esa es la suerte del malvado, el destino del que desconoce a Dios (Job 18, 2-6 y 21).

Este pasaje del Antiguo Testamento parece dedicado al autor de la Spongia, que en la Expostulatio es retratado como un escarabajo, es decir, como aquel que no sigue las leyes divinas. Además con una vela encendida sobre el lomo, que según el texto que acabamos de citar le calificaría como un hombre perverso.

17. Ni siquiera entre los amplios y valiosos catálogos del Grupo de Investigación «Literatura emblemática hispánica» (Universidad de La Coruña) hemos descubierto un posible antecedente o prototipo. 
Una última incógnita giraría en torno al papel que tendrían estos «niños» que escarmientan al insecto. En realidad no son críos exactamente, sino muchachos, ya que la palabra latina puer puede comprender un amplio rango de edad, alcanzando también al adolescente o joven adulto. Por ende, estaríamos ante estudiantes, esto es, sus propios pupilos en la Complutense, porque no podemos olvidar que Torres Rámila era maestro de gramática latina en esta universidad por aquel entonces ${ }^{18}$. De hecho, en otros lugares de la Expostulatio se utiliza el término puer cuando se hace mención a sus alumnos ${ }^{19}$, de quienes se dice que tenían una opinión nefasta sobre él: «Entretanto, no se apartó del estudio superficial de la amada gramática, hasta que sus alumnos fueron testigos de su ignorancia supina al tener que repetir cien veces el mismo tema ${ }^{20}$.

Ellos son quienes lo marcan con la luz de los infames, pues lo tratan a diario en el aula y lo conocen mejor que nadie. Sin embargo, no haría falta marcarle con vela tan ignominiosa, pues como advierte el autor en ambos emblemas, su propio mal olor ya lo delata y lo condena. Vale.

18. No hay que pasar por alto el hecho de que el burgalés era además estudiante de Teología durante los ańos de la polémica, por lo que acusarle de estar al margen del conocimiento de Dios también tendría un fuerte componente burlesco.

19. Cf. Julián González-Barrera, Expostulatio..., p. 250, 264 y 284. Conviene señalar que en la Expostulatio nunca se emplea para los estudiantes otro término que implique una categorización por edad, como por ejemplo adulescens, que Julio Columbario utiliza solo para referirse a sí mismo.

20. "nec interea a triviali amatae grammatistices studio destitit, quin discipulos ignarae ruditatis vindices habuit, eandem incudem frustra tundendo» (Cf. ibidem, p. 130-131). 